\title{
Spouses who placed partners in care homes experienced emotional reactions to separation and made efforts to maintain their relationship
}

\author{
Sandberg J, Lundh U, Nolan MR. Placing a spouse in a care home: the importance of keeping. J Clin Nurs 2001 \\ May;10:406-16.

\section{QUESTION: What are the experiences of family carers after placing a spouse in a care home?}

Design

Grounded theory.

Sources of funding: Swedish Foundation for Health Care Sciences and Allergy Research and Vårdal Foundation.

For correspondence: Mr J Sandberg,

Department of

Neuroscience and

Locomotion, Division of

Geriatrics, Linköping

University, $S-58185$

Linköping, Sweden.

jonassandberg@

mail.bip.net

\section{Participants}

\section{Methods}

\section{Setting \\ A municipality in southern Sweden.}

12 spouses $\{8$ wives and 4 husbands $\}$ * who had placed a partner in a care home within the past 6-12 months.

In semistructured interviews, participants were asked about their experiences after admitting a spouse to a care home. Interviews were audiotaped and transcribed.

\section{COMMENTARY}

The grounded theory study by Sandberg $e t$ al provides an important view of spouses who place their partners in care homes. It is one of few studies examining spouses and the relationship between families and care home staff. The authors indicated how ill prepared family members were for separating from their loved ones and integrating into a new care system. Forming relationships with care home staff appeared to be difficult for family members. Families wanted to have equitable and explicit roles and relationships with the agency staff that were beneficial to the patient. Family carers should be helped to prepare for the separation from their partner and form new relationships with their partner and the care home staff.

Caution must be taken in generalising the findings of this study because only 12 spouses who had placed a partner in a care home in the previous 6-12 months were interviewed. Investigators are just beginning to study this major family transition, and no conclusions can be drawn at this time.

This study does, however, raise several issues for future research. The viewpoints of agency staff need to be considered as part of the research questions. Models of care should be developed, implemented, and tested for effectiveness in promoting family integration into the care home system. Potential strategies for staff have been suggested by Nolan and Dellasega ${ }^{1}$ and include (1) helping carers view their spouse's placement in a care home in a positive light by acknowledging their need to both give and receive help, (2) helping carers to recognise and deal with their ambivalent emotions, (3) creating an environment that encourages and supports the carer's role, (4) maximising the involvement of carers and facilitating a sense of purpose, (5) valuing carers' knowledge and using it to inform planning, and (6) encouraging a partnership approach of carers and staff.

This study offers a perspective for nurses to consider as they work with families placing an elderly member in a care home. If nurses and other staff recognise the values of the family and integrate them into care, positive outcomes could occur for all.

Barbara Given, RN, PhD

University Distinguished Professor College of Nursing, Michigan State University

East Lansing, Michigan, USA

1 Nolan M, Dellasega C. 'It's not the same as him being at home': creating caring partnerships following nursing home placement. J Clin Nurs 1999;8:723-30.

Constant comparison was used to elaborate on the themes derived from a previous set of interviews, particularly the processes of separation and continuity in maintaining relationships ("keeping").

\section{Main findings}

The process of separation included 4 elements: pretending, dawning, putting on a brave face, and seeking solace. Pretending involved the carers convincing themselves that their spouse's admission to a care home was simply a trial separation and was not permanent. Dawning referred to the growing awareness that the placement was permanent. Subverting their feelings and needs led the carers to putting on a brave face, which could continue long after the admission of their partner to the care home. Some carers would seek solace and attempt to discuss their feelings with relatives, friends, and professionals. In most cases, however, the focus of attention was on the spouse entering the care home, and the carer's needs were not addressed.

The core theme of keeping explained carers' efforts to maintain their relationship with their spouse. Initially, an urgency existed to keep it going and spouses attempted to sustain near normal relationships. The carers had practical tasks that gave them a sense of active involvement with their spouses. Carers also described efforts to keep in touch and keep it special. They tried to keep their spouses in touch with previous pastimes, hobbies, and social contacts. Keeping it special involved attention to the spouse's personal preferences and rituals that had developed between the carer and spouse. Carers also engaged in keeping an eye on the care that staff provided to their spouse. Interactions with care staff ranged from keeping your distance (minimal contact with staff), keeping quiet (engaging staff on a polite but superficial level), keeping on trying (carers role modelled care they wanted staff to provide), to keeping it close (carers and staff working in partnership).

\section{Conclusions}

The process of separation experienced by family carers after placing a spouse in a care home included 4 elements: pretending, dawning, putting on a brave face, and seeking solace. The theme of "keeping" emerged as key in the attempts of carers to maintain relationships with their spouses.

*Information provided by author. 